\title{
PELATIHAN BRANDING DAN PACKAGING KERAJINAN KAIN FLANEL DI PANTI ASUHAN MUHAMMADIYAH BUDI UTOMO KOTA METRO
}

\author{
Tiara Anggia Dewi ${ }^{1}$, Ningrum ${ }^{2}$, Yeni Rahmawati ES. ${ }^{3}$ \\ Universitas Muhammadiyah Metro, Metro ${ }^{1}$ \\ Universitas Muhammadiyah Metro, Metro ${ }^{2}$ \\ Universitas Muhammadiyah Metro, Metro ${ }^{3}$ \\ tiara.anggia.d@gmail.com
}

\begin{abstract}
ABSTRAK
Pengabdian yang dilakukan adalah pelatihan pembuatan Branding dan Packaging Produk. Kegiatan pelatihan ini merupakan tindak lanjut dari pelatihan kewirausahaan pembuatan kerajinan dari kain flanel yang sebelumnya telah dilaksanakan pada anak-anak di Panti Asuhan Muhammadiyah Budi Utomo Kota Metro. Dalam kegiatannya terdiri dari dua kali pertemuan yakni memberikan pelatihan dengan tahapan teori dan praktek. Dalam kegiatan pengabdian ini terdapat beberapa tahapan diantaranya yaitu tahap persiapan, tahap pelaksanaan dan tahap pelaporan. Dengan diadakannya pelatihan ini diharapkan peserta dapat memiliki pengetahuan dan ketrampilan mengenai perencanaan strategi pemasaran produk dengan membuat branding serta packaging produk yang menarik, sehingga produk kerajinan kain flannel yang telah dibuat dapat dikembangkan dan diterima dengan baik serta diminati konsumen.
\end{abstract}

Kata Kunci :Branding, Packaging, Kewirausahaan

\begin{abstract}
The dedication that was carried out was training on the manufacture of Branding and Product Packaging. This training activity is a follow-up to the entrepreneurship training of making handicrafts from flannel which had previously been carried out for children at the Muhammadiyah Budi Utomo Orphanage, Metro City. The activity consists of two meetings, namely providing training with theoretical and practical stages. In this service activity there are several stages including the preparation stage, the implementation stage and the reporting stage. By holding this training, it is hoped that participants will have knowledge and skills regarding planning product marketing strategies by making attractive branding and product packaging, so that the flannel craft products that have been made can be developed and are well accepted and are of interest to consumers.
\end{abstract}

Kata Kunci :Branding, Packaging,Entrepreneurship

\section{LATAR BELAKANG}

Anak-anak yang berada di naungan Panti Asuhan Budi Utomo Kota Metro, sudah pernah melakukan kegiatan pelatihan tentang pembuatan kerajinan dari kain flannel.Hal ini menjadi bekal mereka untuk dapat bertahan hidup dan bersaing secara sehat pada dunia kerja di dalam masyarakat. Tetapi, pembuatan produk yang baik harus di iringi dengan sistem pemasaran yang baik juga. Di awali dengan pembuatan merk (branding) dan memberikan kemasan yang menarik (packaging). 
Menurut Boomsma \& Arnoldus (2008) brand diciptakan untuk meyakinkan calon konsumen mengenai keunggulan standar kualitas, reliabilitas, status sosial, nilai, atau keamanan sebuah produk.Simmons (2007) menyatakan bahwa seorang yang menciptakan brand terhadap suatu produk atau jasa haruslah berusaha membangun relasi kuat antara produk atau jasanya dengan pelanggannya. Hal ini akan semakin memperkuat daya saing produk atau jasanya tersebut ke depannya dan menjadikannya semakin sulit bagi pesaing untuk menirunya.

Layaknya brand, maka branding juga memiliki beberapa pengertian tergantung sudut pandang penggunaannya.Secara awam, branding dipahami sebagai kegiatan promosi, iklan, atau publisitas.

Branding adalah proses mendesain, merencanakan, dan mengkomunikasikan nama serta identitas dengan tujuan membangun atau mengelola reputasi (Anholt, 2003). Diferensiasi adalah alasan adanya branding. Diferensiasi adalah proses mengubah komoditas menjadi brand yang kuat. Diferensiasi meliputi: a) Menemukan dan memiliki penawaran penjualan yang unik (USP); b) Menemukan strategi tepat untuk membantu brand anda mendapat keuntungan kompetitif; c) Menemukan diferensiator yang relevan bagi pembeli anda, menarik dan dapat dipertahankan.

Oleh karena itu, sangat penting untuk menentukan brand image dalam produksi barang yang dihasilkan.Dengan adanya citra merek (brand image) produk yang dihasilkan dapat memiliki ciri khas yang mampu menjadikan pembeda antara produk lainnya sehingga dapat menarik minat konsumen.

Kotler dan Amstrong (2012) mendefinisikan "packaging involves designing and producing the container or wrapper for a product" yang artinya adalah proses kemasan melibatkan kegiatan mendesain dan memproduksi, fungsi utama dari kemasan sendiri yaitu untuk melindungi produk agar produk tetap terjaga kualitasnya.

Di masa era globalisasi sekarang ini packaging semakin meningkat perkembangannya, misal untuk membawa produk-produk yang bernilai kapasitas besar dan memiliki produk bernilai teknologi tinggi seperti : alat berat, mobil, perangkat peralatan bernilai elektronik. Packagingnya pun memiliki nilai tinggi demi menyelamatkan produk tidak rusak, sampai perihal limbah-limbah packaging pun bisa dimanfaatkan untuk produk yang mempunyai nilai tinggi dan seni tinggi yang tepat guna, banyak diminati oleh para calon konsumen (Mukhtar $\&$ Nurif, 2015) 
Proses produksi harus memperhatikan beberapa hal yang dapat mendukung baik faktor internal maupun eksternal.Menurut Nugroho (2010) dalam berwirausaha beberapa hal yang harus diperhatikan yaitu mempunyai sifat disiplin, berani terhadap resiko, jujur dan ulet, serta pekerja keras, kretif dan inovatif. Berikut merupakan alur yang harus dilalui seseorang untuk melakukan wirausaha:

\section{Perencanaan/memulai}

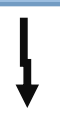

Pelaksanaan usaha Mempertahankan usaha Mengembangkan

\section{Gambar 1.Tahapan Berwirausaha Sumber: Nugroho (2010)}

Untuk mampu bertahan di dunia usaha maka diperlukan daya kreativitas yang tinggi. Dilandasi oleh daya pikir yang maju serta penuh dengan gagasan-gagasan baru yang berbeda dari produk-produk yang sudah ada sebelumnya salah satunya yaitu dengan kepemilikan branding dan packaging yang baik.

Penggunaan merek dan kemasan yang baik dapat mendorong penjualan serta membangun tingkat kepercayaan konsumen.Kemasan yang menarik dapat memperindah serta menjamin keamanan produk agar tidak mudah rusak saat dipasarkan.Selain itu, peluang inovasi yang dilakukan saat ini mampu membawa manfaat yang besar baik bagi produsen maupun konsumen.

Berdasarkan latar belakang di atas, maka kegiatan pengabdian masyarakat berupa pelatihan pembuatan branding dan packaging ini perlu untuk dilaksanakan untuk memberikan wawasan serta ketrampilan tentang desain dan kemasan menarik yang membuat produk menjadi lebih bernilai dan aman.

\section{METODE PELAKSANAAN}

Metode yang dilakukan dalam kegiatan pengabdian ini adalah dengan memberikan pelatihan langsung (ceramah, demonstrasi, dan tanya jawab) kepada anak-anak di Panti Asuhan Muhammadiyah Budi Utomo Kota MetroKegiatan ini dihadiri oleh 26 orang.

Adapun tahapan-tahapan yang dilakukan dalam pengabdian iniadalah :

a. Tahap Persiapan 
Tahapan dalam pelaksanaan pengabdian ini yaitu: 1) Membuat surat izin pengabdian, 2) Koordinasi dengan Mitra di Lokasi, 3) Penyiapan Mitra yang kompeten dan relevan dengan materi yang disiapkan, 4) Penyiapan materi pelatihan tentang image branding dan packaging, dan 5) Menentukan waktu jadwal pengabdian.

\section{b. Tahap Pelaksanaan}

Adapun tahapan dalam pengabdian ini yaitu: 1) Menentukan sampel,yaitu anakanak yatim piatu yang sudah berumur di atas 10 tahun. 2) Melaksanakan pengabdian melalui pelatihan Image branding dan packaging dalam panti asuhan Muhammadiyah Budi Utomo Kota Metro yaitu pemberian materi dan diskusi dilanjutkan praktik pembuatan brand atau merek dan packaging atau pengemasan. Pemberian materi berlangsung selama 4 jam sebanyak 2 kali pertemuan. Materi yang disampaikan antara lain tentang cara membuat merk dan pemilihan kemasan yang menarik.

\section{c. Tahap Akhir}

Tahap akhir pengabdian yaitu menganalisis hasil pelatihan.

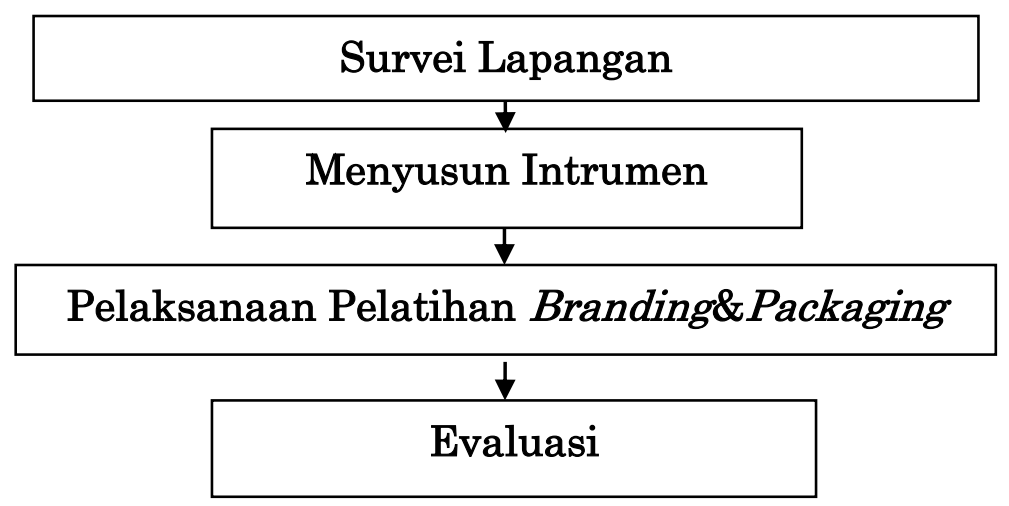

Gambar 2.Tahapan Pengabdian

Materi Pelatihan Branding dan Packagingtersaji pada tabel 1 berikut.

Tabel 1 Materi Pengabdian yang Akan Dilaksanakan

\begin{tabular}{llll}
\hline No & $\begin{array}{l}\text { Materi } \\
\text { Pengabdian }\end{array}$ & $\begin{array}{c}\text { Jumlah } \\
\text { Jam }\end{array}$ & \multicolumn{1}{c}{ Tujuan } \\
\cline { 2 - 3 } & MATERI PELATIHAN & \\
\cline { 2 - 3 } & Hari ke-1 & 1 jam & $\begin{array}{l}\text { Mitra dapat mengetahui bahan-bahan } \\
\text { yang akan digunakan untuk }\end{array}$ \\
\hline 1 & $\begin{array}{l}\text { Menjelaskan } \\
\text { Bahan-bahan dan } \\
\text { harga bahan } \\
\text { pembuatan merek } \\
\text { dan kemasan }\end{array}$ & $\begin{array}{l}\text { pembuatan merek dan kemasan serta } \\
\text { harga untuk membeli bahan }\end{array}$ \\
\end{tabular}




\begin{tabular}{|c|c|c|c|}
\hline 2 & $\begin{array}{l}\text { Menjelaskan } \\
\text { teknik pembuatan } \\
\text { branding } \\
\text { danpackaging }\end{array}$ & 1 jam & $\begin{array}{l}\text { Mitra dapat memahami dan } \\
\text { mempelajari teknik pembuatan } \\
\text { desain logo merek dan pembuatan } \\
\text { kemasan }\end{array}$ \\
\hline \multirow[t]{2}{*}{3} & $\begin{array}{l}\text { Membuat } \\
\text { rancangan brand } \\
\text { (merek) dan } \\
\text { packaging }\end{array}$ & 2 jam & $\begin{array}{l}\text { Mitra dapat membuat rancangan } \\
\text { brand (merek) dan packaging }\end{array}$ \\
\hline & Hari ke-2 & & \\
\hline 4 & $\begin{array}{l}\text { Membuat desain } \\
\text { brand (merek) dan } \\
\text { packaging }\end{array}$ & 4 jam & $\begin{array}{l}\text { Mitra membuat desain logo merek } \\
\text { yang diinginkan dan membuat } \\
\text { packaging untuk mengemas } \\
\text { kerajinan kain flanel }\end{array}$ \\
\hline
\end{tabular}

\section{HASIL, PEMBAHASAN, DAN DAMPAK}

Pengabdian Masyarakat telah dilaksanakan pada hari Sabtu dan Minggu tanggal 18-19 bulan Juli tahun 2020 bertempat di Aula Yayasan Panti Asuhan Muhammadiyah Budi Utomo Kota Metro. Peserta kegiatan pengabdian masyarakat ini berasal dari anak-anak panti asuhan muhammadiyah Budi Utomo Metro berjumlah26 orang anak.

Pada pelatihan pada hari pertama yang dilaksanakan pada hari sabtu tanggal 18 Juli 2020 pukul 13.00-15.00 WIB peserta diberikan informasi mengenai bahan-bahan yang akan digunakan untuk pembuatan merek dan kemasan serta harga untuk membeli bahan agar peserta dapat memahami dan mempelajari hal-hal apa saja yang perlu dipersiapkan dalam pembuatan desain logo merek dan pembuatan kemasan.Berikut adalah dokumentasi selama kegiatan berlangsung.

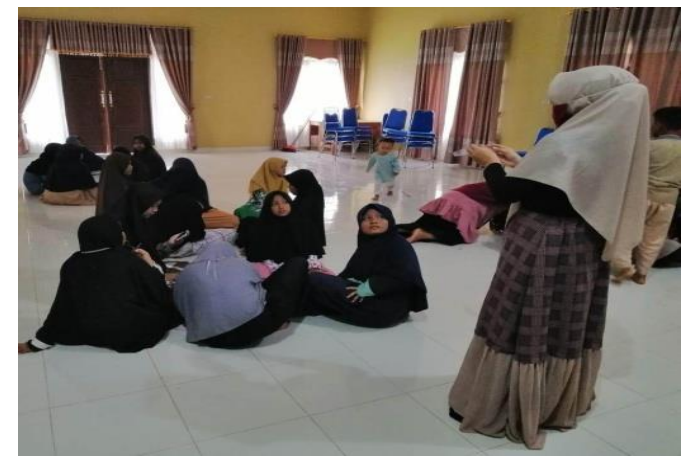

Gambar 3. Pengenalan Alat dan Bahan Pembuatan Packaging 
Gambar 3 merupakan kegiatan hari pertama pengabdian, yang mana tim pengabdi memberikan informasi atau mengenalkan bahan dan alat untuk branding dan packaging kepada anak-anak panti asuhan.
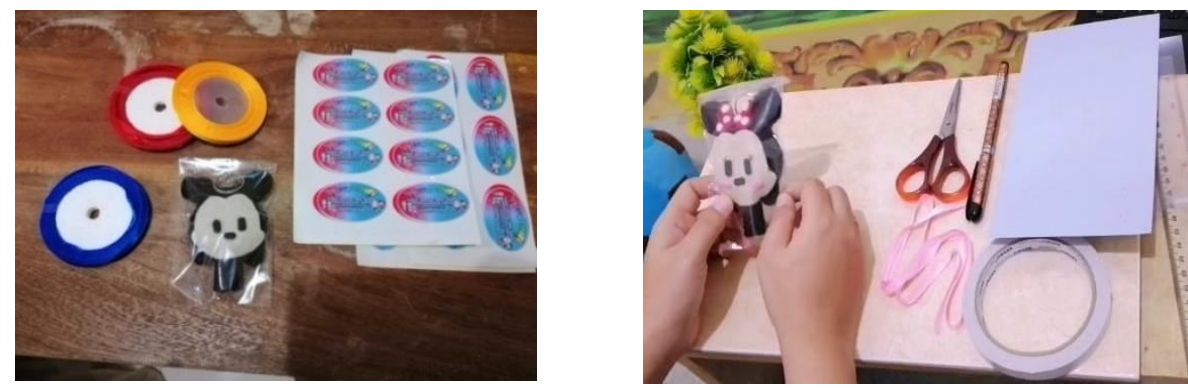

\section{Gambar 4. Alat dan Bahan Branding dan Packaging}

Gambar 4 adalah alat dan bahan yang dibutuhkan untuk pelatihan branding dan packaging.Adapun alat dan bahan tersebut adalah gunting, pita, lem tembak, double tip, bolpin, kertas karton, plastik, mika.

Pelatihan hari kedua yang dilaksanakan tanggal 19 Juli 2020 pukul 09.00-12.00.Peserta melakukan praktik pembuatan packaging untuk mengemas kerajinan kain flannel yang berupa gantungan kunci. Sebelumnya, peserta terlebih dahulu diberikan pengetahuan mengenai cara pembuatan merek/logo produk oleh ahli desain grafis yang bernama Alan Hadi Kusuma melalui video.

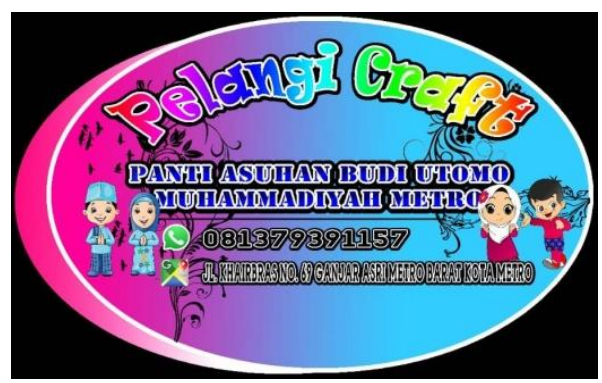

Gambar 5. Brand/Merek yang sudah jadi

Gambar 5merupakan hasil brand/merek yang di rancang oleh ahli desain untuk produk kerajinan kain flannel bagi anak-anak panti asuhan Muhammadiyah Budi Utomo Kota Metro. Label merek terdiri dari nama brand/merek, nomor whatsapp dan alamat pembuat kerajinan. Nama merek yang dibuat yaitu "Pelangi Craft", nama diambil dari filosofi kehidupan anakanak dipanti yang penuh warna-warni. Selama proses penyampaian materi dan latihan, peserta dapat mengajukan pertanyaan mengenai hal-hal yang belum jelas dan belum 
dipahaminya. Selama kegiatan praktek, anak-anak panti asuhan mengikuti dengan sangat antusias.

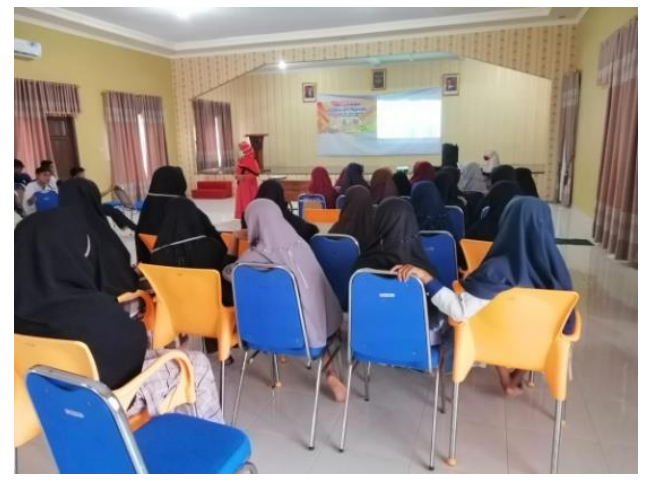

Gambar 6. Pemberian Materi Dasar Tentang Branding dan Packaging

Gambar 6 merupakan kegiatan penyampaian materi tentang Branding dan Packaging yang disampaikan oleh Tiara Anggia Dewi.Materi yang disampaikan berkaitan dengan definisi, manfaat serta langkah-langkah.

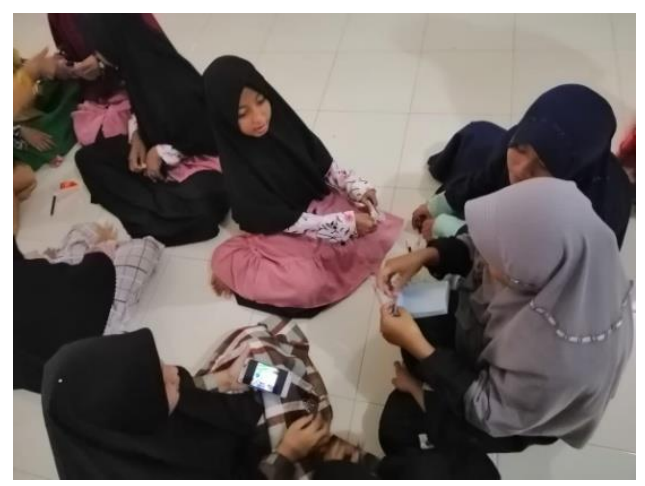

\section{Gambar 7. Praktik Pembuatan Packaging}

Gambar 7 merupakan kegiatan praktek mengemas gantungan kunci. Tim pengabdi mendemontrasikan cara mengemas gantungan kunci, yang selanjutnya anak-anak peserta pelatihan mempraktekkan langsung yang dimulai dengan memotong dan membentuk kertas karton menjadi bentuk balok yang atapnya terbuka.

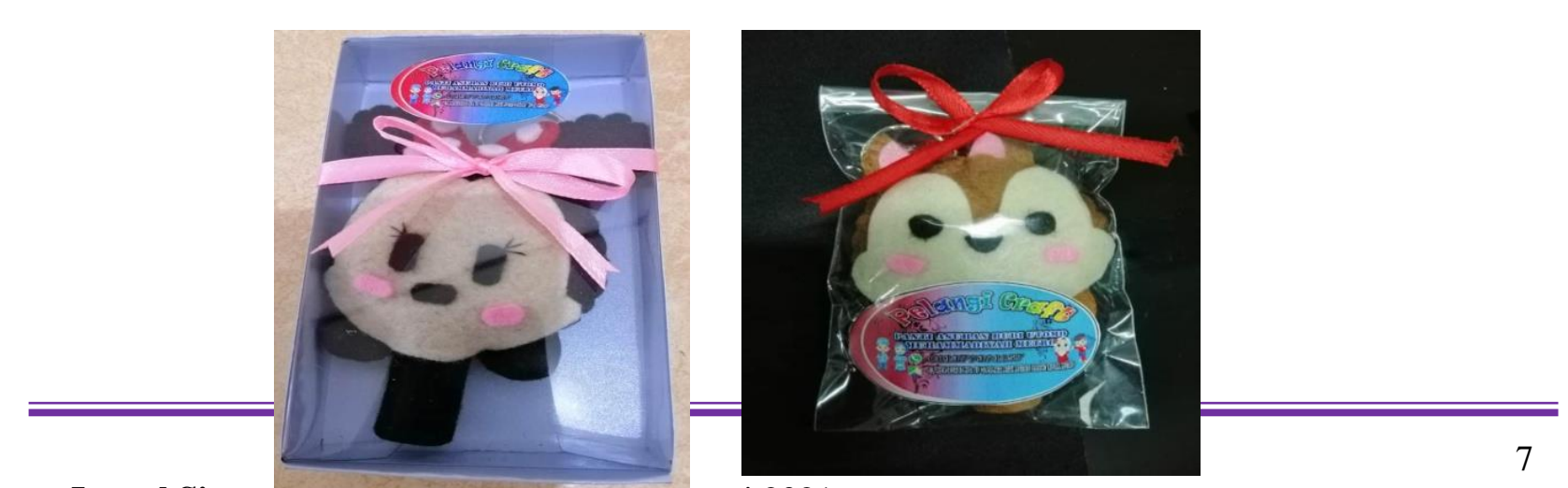




\section{Gambar 8.Sampel Packaging yang Sudah Jadi}

Gambar 8 adalah sampel hasil akhir pembuatan branding dan packaging kerajinan kain flannel yang dibuat oleh anak-anak panti asuhan Muhammadiyah Budi Utomo.

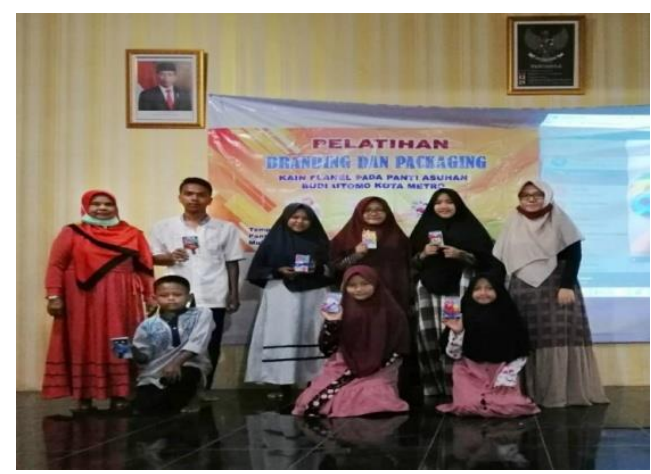

\section{Gambar 9. Foto Tim Pengabdi Bersama Anak-Anak Panti Asuhan Muhammadiyah Budi Utomo}

Gambar 9 adalah dokumentasi tim pengabdi bersama anak-anak Panti Asuhan Muhammadiyah Budi Utomo Metro setelah dilaksanakan kegiatan pelatihan branding dan packaging.

\section{SIMPULAN}

Anak-anak peserta kegiatan pelatihan merasa senang dan bersyukur karena diberikan ilmu yang sangat bermanfaat sekali bagi mereka. Dengan pelatihan yang diberikan, mereka dapat mendesain brand dan mengemas produkyang dimiliki dalam berbagai variasi bentuk dan model berdasarkan kreatifitas mereka. Sehingga produk yang dijual dapat lebih dikenal dan diminati oleh masyarakat di penjuru tanah air.

\section{UCAPAN TERIMAKASIH}

Tim pengabdi mengucapkan terima kasih kepada semua pihak yang telah membantu kegiatan pelatihan ini, khususnya kepada Lembaga Pengabdian Pada Masyarakat (LPPM) Universitas Muhammadiyah Metro yang telah mendanai kegiatan pengabdian ini sehingga terlaksana dengan baik. 


\section{DAFTAR RUJUKAN}

Anholt, Simon. 2003. Brand New Justice: Branding Places and Products Help the Developing World. London: Elsevier.

Amstrong, G. \& Kotler.P.2012. Prinsip-Prinsip Pemasaran.Cetakan pertama.

Boomsma, M. \& Arnoldus, M. 2008.Branding for Development.KIT Working Papers Series C2. Amsterdam: KIT

Mukhtar, S. \& Nurif, M. 2015.Peranan Packaging Dalam Meningkatkan Hasil Produksi Terhadap Konsumen. Jurnal Sosial Humaniora, Vol 8 No.2, pp: 181 - 191

Nugroho,Niti. 2010. Kewirausahaan Dan Manajemen Industri Kecil.

Simmons, G. J. 2007. I-BRANDING : Deeloping the Internet as a Branding Tool. Marketing Intellegence \& Planning, Vol.25 (6) , pp.544-562 